NASA/TM-2004-212725

\title{
Observation of Dust Stream Formation Produced by Low Current, High Voltage Cathode Spots
}

John E. Foster

Glenn Research Center, Cleveland, Ohio 
Since its founding, NASA has been dedicated to the advancement of aeronautics and space science. The NASA Scientific and Technical Information (STI) Program Office plays a key part in helping NASA maintain this important role.

The NASA STI Program Office is operated by Langley Research Center, the Lead Center for NASA's scientific and technical information. The NASA STI Program Office provides access to the NASA STI Database, the largest collection of aeronautical and space science STI in the world. The Program Office is also NASA's institutional mechanism for disseminating the results of its research and development activities. These results are published by NASA in the NASA STI Report Series, which includes the following report types:

- TECHNICAL PUBLICATION. Reports of completed research or a major significant phase of research that present the results of NASA programs and include extensive data or theoretical analysis. Includes compilations of significant scientific and technical data and information deemed to be of continuing reference value. NASA's counterpart of peerreviewed formal professional papers but has less stringent limitations on manuscript length and extent of graphic presentations.

- TECHNICAL MEMORANDUM. Scientific and technical findings that are preliminary or of specialized interest, e.g., quick release reports, working papers, and bibliographies that contain minimal annotation. Does not contain extensive analysis.

- CONTRACTOR REPORT. Scientific and technical findings by NASA-sponsored contractors and grantees.
- CONFERENCE PUBLICATION. Collected papers from scientific and technical conferences, symposia, seminars, or other meetings sponsored or cosponsored by NASA.

- SPECIAL PUBLICATION. Scientific, technical, or historical information from NASA programs, projects, and missions, often concerned with subjects having substantial public interest.

- TECHNICAL TRANSLATION. Englishlanguage translations of foreign scientific and technical material pertinent to NASA's mission.

Specialized services that complement the STI Program Office's diverse offerings include creating custom thesauri, building customized databases, organizing and publishing research results ... even providing videos.

For more information about the NASA STI Program Office, see the following:

- Access the NASA STI Program Home Page at http://www.sti.nasa.gov

- E-mail your question via the Internet to help@sti.nasa.gov

- Fax your question to the NASA Access Help Desk at 301-621-0134

- Telephone the NASA Access Help Desk at 301-621-0390

- Write to:

NASA Access Help Desk

NASA Center for AeroSpace Information 7121 Standard Drive

Hanover, MD 21076 
NASA/TM-2004-212725

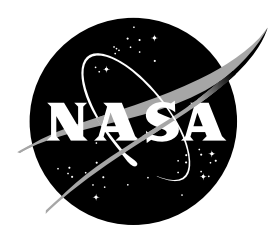

\section{Observation of Dust Stream Formation Produced by Low Current, High Voltage Cathode Spots}

John E. Foster

Glenn Research Center, Cleveland, Ohio

National Aeronautics and

Space Administration

Glenn Research Center 


\section{Acknowledgments}

I would like to recognize Robert Roman for assistance in the design of the dust source. Additionally, I would also like to recognize Donna Neville for assistance in carrying out the many dusty plasma experiments.

Available from

NASA Center for Aerospace Information 7121 Standard Drive

Hanover, MD 21076
National Technical Information Service 5285 Port Royal Road Springfield, VA 22100

Available electronically at http:/ /gltrs.grc.nasa.gov 


\title{
Observation of Dust Stream Formation Produced by Low Current, High Voltage Cathode Spots
}

\author{
John E. Foster \\ National Aeronautics and Space Administration \\ Glenn Research Center \\ Cleveland, Ohio 44135
}

\begin{abstract}
Macro-particle acceleration driven by low current, high voltage cathode spots has been investigated. The phenomenon was observed to occur when nanometer and micrometer-sized particles in the presence of a discharge plasma were exposed to a high voltage pulse. The negative voltage pulse initiates the formation of multiple, high voltage, low current cathode spots which provides the mechanism of actual acceleration of the charged dust particles. Dust streams generated by this process were detected using laser scattering techniques. The particle impact craters observed at the surface of downstream witness badges were documented using SEM and light microscopy.
\end{abstract}

\section{Introduction}

The risk of damage to spacecraft and satellites by orbital debris or micro-meteoroid impacts is an ever present possibility whose probability increases with exposure time. Long on-orbit times or long transit time science missions are at risk for some level of impact damage. Damage to structures such as tethers due to micrometeoroids is particularly problematic. ${ }^{1,2}$ Impact damage due to long duration exposure in space has been assessed by studying exposed surfaces of spacecraft such as the Long Duration Exposure Facility, the Hubble space telescope and the surfaces on the Solar Maximum Mission spacecraft. ${ }^{2}$ The level of damage can be expected to be even higher for missions to dusty environments such as comets and planetary ring systems or during meteor showers. ${ }^{3}$ In this regard the need to fully understand the effects of energetic impacts caused by micro-meteoroids in such environments is important.

As shown in prior studies, energetic particle impacts can lead to damage or even catastrophic failure of space-probe or satellite subsystems. ${ }^{1,2,4}$ The damage from micrometeoroids can be mechanical in nature, where hypervelocity impacts can give rise to cratering, fragmentation, or melting/evaporation processes on spacecraft surfaces. For very high velocity impacts (>10 km/s) plasma formation driven by impact ionization can occur. ${ }^{5}$ This can lead to shorting and subsequent failure of electronic components. ${ }^{1}$ Secondary ejecta from micrometeoroid impacts can also damage spacecraft subsystems. ${ }^{6}$

The simulation of energetic impacts between naturally occurring space dust ( $<1 \mathrm{~mm}$ typical) and spacecraft surfaces is primarily done with heavy particle accelerators. ${ }^{1,7,8}$ Acceleration of small, micron-sized man-made particles such as alumina oxide spheroids generated by solid rocket motors can also be simulated with this type of accelerator. Heavy particle accelerators utilize field emission to charge the particles of interest. Subsequently, the particles are levitated and then injected into a high-energy acceleration stage (MV) typical driven by a Van de Graf generator. ${ }^{7,8}$ Simulation of much larger particles to assess man-made orbital debris and larger 
micro-meteoroids is done primarily with light gas guns. ${ }^{1,7}$ Light gas guns utilize an explosive that drives a piston which in turn compresses a light gas such as hydrogen or helium to high pressures against a diaphragm. Rupture of the diaphragm generates a shock wave that accelerates the particles to very high velocities. Both techniques can accelerate particles to over $5 \mathrm{~km} / \mathrm{s}$. Though effective in many respects, the light gas guns and heavy particle accelerators require complex, large facilities that are expensive to operate. Additionally, the duty cycles for such facilities are low as well. ${ }^{7}$

This study investigates the potential use of a low temperature discharge plasma to charge small particles $(\mathrm{nm}-\mu \mathrm{m})$ and then accelerate them using a voltage pulse. This approach could potentially lead to the development of smaller-scale, low cost, bench-top hypervelocity impact experiments. Such a tool can be used for accelerated life-testing of spacecraft components as part of spaceflight qualification for those missions where long term exposure to micrometeoroid streams and dusty environments is a risk.

It has been shown that films or coatings of nano-particles can enhance optical and surface properties of various materials. ${ }^{9}$ In this respect, the particle accelerator approach under investigation here could also have industrial applications in that it can be used for the deposition or implantation of nano-particles into substrates. By varying plasma properties and the magnitude of the voltage pulse, particle energy and dosage could be controlled.

Reported here are observations of the formation of particle streams under the action of low current, high voltage cathode spots. Cathode spot behavior was documented using a CCD camera. Subsequent dust streams formed were studied using laser scattering experiments and "witness" plate targets located downstream of the dust particle accelerator.

\section{Conceptual Description of Dust Particle Accelerator Approach}

The dust particle accelerator takes advantage of basic plasma properties to achieve both charging and acceleration of particulates. In general, any isolated body (conductor or insulator) immersed in a plasma will develop a net charge depending on the relative mobilities of the charge constituents in the discharge and radiation processes. ${ }^{10,11}$ In low temperature, partially ionized plasmas, the average kinetic energy of an electron is much greater than that of the ions and as a result an exposed body charges negatively. The negative potential on the body (floating potential) adjusts itself to the point where the collected flux of ions and electrons are equal

$$
0.61 \cdot e \cdot n_{e} \cdot \sqrt{\frac{k T_{e}}{m_{i}}}=\frac{1}{4} \cdot e \cdot n_{e} e^{\frac{e\left(V_{f}-V_{p}\right)}{k T_{e}}} \cdot \sqrt{\frac{8 \cdot k T_{e}}{\pi \cdot m_{e}}}
$$

Here, the floating potential is $V_{f}$, the plasma density is $n_{e}$, the elementary charge on the electron is $e$, the mass of the electron and ion respectively is $m_{e}$ and $m_{i}$, the local plasma potential is $V_{p}$, and the electron temperature is $T_{e}$.

The dust accelerator utilizes the fact that isolated, non-conducting particles immersed in a plasma will charge up in the manner previously described. Figure 1 presents a conceptual depiction of the operation of the dust particle accelerator. A dust holder containing small, insulating particles or dust is exposed to a discharge plasma. The dust surface facing the plasma will charge up. The charge on each particle depends on the floating potential and capacitance of the particle. Assuming the particle is spherical in shape, the capacitance of the particle is 


$$
C=4 \cdot \pi \cdot \varepsilon_{o} \cdot r
$$

where $\varepsilon_{0}$ is the dielectric permittivity of free space and $r$ is the radius of the dust particle. The maximum charge on the particle can then be estimated by multiplying the capacitance by the floating potential ${ }^{11}$

$$
Q=C \cdot V_{f}
$$

Studies have shown that for plasma densities $\sim 10^{10} / \mathrm{cm}^{3}$ and electron temperatures of order 2 to $5 \mathrm{eV}$ (similar to those generated in this investigation), 40 micron diameter particulates can accumulate very large negative charges - over $10^{6}$ electrons. ${ }^{12}$ Upon charging, if a large negative sheath potential could be imposed at the dust surface, then the charged dust could be accelerated to energies equal to the sheath voltage multiplied by the total charge on the particle: $E=q \cdot V_{s}$. Here $V_{s}$ is the potential difference across the sheath originating at the surface of the dust and q is the total charge on a given dust particle. The establishment and maintenance of a large negative sheath potential originating at the surface of the dust particle layer is in general problematic. If an insulator-covered electrode is immersed in a discharge plasma, the non-conductive side will assume a floating potential characteristic of the local plasma environment. Depending on the porosity and thickness of the dust layer lower level particles will charge up to varying degrees. Within the limit of dielectric breakdown of the insulator, the floating potential of the dust particle surface exposed to the plasma will not change with increasing negative bias on the conducting electrode surface. ${ }^{13}$ Very high potential differences and thus very high electric fields can form and grow between near-surface dust particles and the electrode with increasing electrode bias voltage. Indeed, electric fields nearly $10^{8} \mathrm{~V} / \mathrm{m}$ were calculated for dust particles resting on the bias electrode for conditions investigated in this work. Figure 2a illustrates potential profiles for 45 micron alumina particles on metal electrodes. Here the top surface of the dust particles is bounded by an equi-potential surface set at $0 \mathrm{~V}$. This simulates the fixed floating potential of the above plasma. The electrode itself is set at $-1200 \mathrm{~V}$. The actual profiles in a plasma environment will differ somewhat at the surface, but the fields at the electrode surface should be very similar due to the physical shielding effect of the particles. Figure $2 b$ is a close-up of a particle contacting the electrode surface. As can be seen in the figure, electric fields are very intense near the base of the particles. The intensity of the electric field will depend on the particle's curvature. Cathodes spots can be initiated by the very high electric fields present at the surface. ${ }^{14-18}$

In general, cathode spots are typically low voltage, high current, vacuum arc phenomena. Though rare, the low current, high voltage spot has also been documented in the literature. ${ }^{19}$ The low current, high voltage cathode spot can be maintained in the vicinity of a dust particle where the electric field is concentrated. In this regard, the low current spot is constrained to form only in those areas where there are dust particles. Once the spot forms, its sheath will grow to meet the main discharge plasma sheath boundary at the surface of the dust layer. The spatial extent of this sheath represents that area of influence of the cathode spot.

A high voltage cathode spot can be employed to accelerate the highly charged dust particles lying on the electrode. Provided the sheath thickness associated with the cathode spot is large compared to the dust particle's characteristic length scale, the potential difference associated with the cathode spot can electrostatically accelerate the charged dust particles that it encounters 
to the full potential difference. As the cathode spot moves along the surface of the electrode, its associated high voltage sheath will accelerate nearby negatively charged particles. The plasma column associated with the cathode spot can also charge up nearby particles, and subsequently accelerate them as well. The high plasma pressure formed at the cathode spot root ${ }^{16,18}$ also locally accelerates dust particles. This process is similar to the plasma drag accelerator used for micrometeoroid simulation. ${ }^{5}$ Intense plasma jets associated with the root of the cathode spot that form at or near dust particles exert accelerating forces on the dust particle. In this regard two forces act on the dust particles to eject them from the dust holder surface.

The dusty plasma accelerator approach described above is expected to be best suited for the acceleration of small, sub-micron sized particles. This follows because the acceleration forces at the electrode will accelerate smaller particles to higher terminal velocities than larger ones. The exit velocity depends on plasma pressure at the electrode as well as the square root of the charge to mass ratio. In general, the surface charge will scale as $r^{2}$ ( $r$ is radius of particle) whereas the mass of the particle will scale as $r^{3}$ leaving the velocity at a fixed bias potential to scale as $\sqrt{\frac{1}{r}}$. Consequently, smaller particles will have the higher initial velocity.

The surface charge on the ejected dust particles will adjust to a steady state value whose magnitude depends in part on the average plasma properties such as plasma density and electron temperature. In this regard, the steady-state charge per particle is calculable. The energy dose imparted from the particle to the target can be adjusted by biasing the target. The incident kinetic energy of the dust particle at the target is then

$$
v=e \cdot V+\frac{\left(2 a s+v_{i}^{2}\right)}{2 m}
$$

Here, a is the acceleration due to gravity, $s$ is the distance between the dust-holding electrode and the target, and $v_{i}$ is the initial velocity of the particle. The second term in equation (4) is associated with particle de-acceleration in the gravity field. As shown in Figure 1, the particles pass through a magnetic grid en rout to the target. The magnetic grid significantly reduces electron flux to the target. ${ }^{20}$

\section{Experimental Set-Up}

The dusty plasma accelerator experiments were performed in a $1 \mathrm{~m}$ diameter by 2.2-m long cylindrical vacuum facility evacuated by a $30 \mathrm{~cm}$ turbo-pump. The pumping speed of the chamber was approximately 2000 liters/s. Typical base pressure was $2 \times 10^{-5}$ Torr. The dusty plasma source consisted of essentially two components: 1) Plasma source and 2) variable bias dust holder. Figure 3a depicts the plasma source itself. The plasma discharge chamber consisted of $30 \mathrm{~cm}$ diameter, $30 \mathrm{~cm}$ long mild steel can containing a ring-cusp magnetic circuit. This ring cusp configuration, which consists of alternating rings of permanent magnets, improves overall discharge performance by enhancing electron containment. Argon gas was injected into the discharge chamber using a gas ring plenum located on the upstream surface of the source. The downstream opening of the discharge chamber was terminated by a grid, which allowed for gas throughput. The grid was electrically isolated from the discharge chamber. The plasma was generated using an internal rf antenna. The internal copper antenna coil utilized in this 
experiment was excited at $13.56 \mathrm{MHz}$. The rf power was matched to the plasma load via a matching network. The discharge was operated between 20 and $120 \mathrm{~W}$ at tank pressures ranging from $8 \times 10^{-5}$ to $1.5 \times 10^{-4}$ Torr. The plasma source was also fitted with three quartz windows whose normals were perpendicular to the source axis. These windows were used to observe the discharge plasma and cathode spot driven dust streams, and to conduct laser scattering experiments.

The electrode which contained the alumina particles (dust holder) consisted of a stainless steel disk mounted in a ceramic (boron nitride) cup. This component is illustrated in Figure $3 \mathrm{~b}$. The assembly rested on the bottom surface of the plasma source. The ceramic cup provided electrical isolation from the discharge chamber, which was held at ground potential. The dust holder was located between two magnet rings of the plasma source. Normally, in this location the magnetic lines of flux would primarily run parallel to the dust electrode's surface, thereby reducing electron flux to the plate. In order to enhance the diffusion of electrons to the dustholding electrode, two rows of samarium-cobalt magnets of alternating polarity were placed behind the stainless steel disk electrode. This created magnetic cusps at the surface of the dustholding electrode. The magnetic cusps were expected to locally improve electron diffusion (and thus charging) to the dust placed on the surface of the disk electrode. As discussed later, it was also found that the magnetic cusps actually controlled the motion of the cathode spots. The bias voltage applied to the dust-holding electrode could be varied from the floating potential to $-1200 \mathrm{~V}$ relative to ground.

In order to roughly characterize plasma properties of the discharge as a function of rf power, a double Langmuir probe was used. As it is a floating probe, it less sensitive to plasma oscillations imposed by the rf antenna than a single Langmuir probe. ${ }^{21}$ The double probe consisted of two $5 \mathrm{~mm}$ long, 0.38 diameter tungsten tips. The probe was mounted such that the probe extended $10 \mathrm{~cm}$ into the discharge chamber. In this regard the probe sampled the core plasma.

The sub-micron to micron sized dust particles used in this investigation were obtained from a commercial source. This investigation reports primarily on observations and measurements using alumina powder with an average diameter of $45 \mu \mathrm{m}$. Figure 4 shows an SEM image of the powder. These particles were placed uniformly over the surface of the dust-holding electrode before each test.

During discharge operation, the dust streams that were produced were difficult to detect by eye because of the broad spectrum brightness of the discharge plasma. In order to visually observe the dust steams, laser light scattering techniques were applied. ${ }^{22}$ In this approach a given volume of the discharge is illuminated by laser light propagating in a specified direction. Laser light scattering was observed perpendicular to the direction of the incident beam through a laser line band pass filter. The use of a single wavelength (632 $\mathrm{nm}$ in this case) in conjunction with a band-pass interference filter greatly improved the clarity of scattering events as acquired using the ccd camera. In this study a $20 \mathrm{~mW}$ helium neon laser was used as the probe beam through the quartz windows of the plasma source. The laser beam was enlarged using a beam expander to illuminate a larger interrogation volume. The laser scattering experimental set-up is illustrated in Figure 5. The acquired images were stored using a digital video recorder.

Witness badges were placed upstream of the dust holder to qualitatively assess the nature of the dust impacts. Carbon badges, placed on the plasma-facing surface of the top window (see windows in Figure 3), were used to collect ejected particles. The badges were analyzed using a 
light microscope as well as a scanning electron microscope to examine dust that collects there during dust stream formation.

\section{Experimental Observations}

Experiments were initiated by placing alumina dust particles of average diameter $45 \mu \mathrm{m}$ onto the dust-holding electrode, inserting the plasma source into the vacuum chamber and then evacuating the chamber. Upon reaching base pressure, argon gas was then fed into the discharge chamber. Excitation of the antenna at $13.56 \mathrm{MHz}$ resulted in gas breakdown and subsequent formation of a steady-state plasma discharge. Impedance matching was excellent with less than 1 $\mathrm{W}$ of reflected power over the entire operating range (20 to $150 \mathrm{~W}$ ). The double probe was used to obtain basic discharge plasma parameters. For the operating conditions investigated in this work the average plasma density was $\sim 10^{10} / \mathrm{cm}^{3}$ and the electron temperature was of order $5 \mathrm{eV}$. The plasma densities near the dust holder were likely somewhat lower than this value as a result of diffusion limited flow due to the strong transverse magnetic field at the walls and the presence of the magnets inside the dust holder itself.

Application of negative voltages (typically lower than -200 V) to the dust holder electrode resulted in observable laser light scattering events. The dust ejection was determined to originate at the observed cathode spots. Cathode spot currents varied between 5 and $10 \mathrm{~mA}$ as measured from the bias power supply. Figure $6 \mathrm{a}$ and $6 \mathrm{~b}$ illustrate dust trajectories made visible via laser light scattering. In general, the scattering events recorded on frame grabs appeared as streaks as shown in the Figure 6. Laser scattering images suggest that there is a distribution in particle sizes that actually leave the dust electrode. Even though there is little spread in average dust particle size, the scattered light signals from the observed particles' trajectories suggest that significantly larger particles or aggregates were being accelerated as well. The parabolic trajectories of these macro-particles can be seen in Figure 6. Note the spread in vertices of the parabolic trajectories. The spread in size (mass) is likely due to particle clumping. Clumping of the alumina dust particles is most likely attributable to the presence of water vapor in the dust sample. Dust holder bake out is a potential solution to this issue. It should also be pointed out that cathode erosion may also contribute to clumping and production of macro-particles. The actual size distribution of dust particles ejected is left to future investigations.

When magnets were used in the dust holder, dust ejection was most pronounced at the magnetic cusps. Indeed the duration of the observed dust streaming was approximately equal to the time it took to remove most of the dust along a magnet pole (approximately along the magnetic cusp line). This selective removal is associated with the fact that the cathode spots were contained along the center of the magnetic cusp. Lateral motion (perpendicular to the cusp line) of the cathode spot was presumably restricted due to the large magnetic field gradients. Figure 7a presents a photograph of the dust removal tracks taken immediately after a test. Here regions thinned out of dust were observed at the magnetic cusp lines and at the edge of the electrode between the magnetic cusps. Figure $7 \mathrm{~b}$ shows a photograph of the electrode with the dust removed revealing a noticeably textured surface. Presumably, the textured surface is an indication of the cathode spot tracks rooted to the electrode itself. The textured regions are roughly equal to the width of the bar magnets in the dust holder. Again, these observations suggest that the cathode spot is rooted along those surfaces near the center of the magnetic cusp. Also observable in the figure are spot foot prints at the edge of the dust holder. Here the magnetic field is very weak $\sim 20 \mathrm{G}$. No dust removal or cathode spot formation was observed in 
the mid-region between the magnetic cusps. Figure 8 show cathode spots as acquired using the ccd camera without the laser filter. The dust electrode was biased to $-800 \mathrm{~V}$ for these cases. In Figure 8a, cathodes spot are observed at the edge of the electrode and at a magnetic cusp. Figure 8b illustrates two spots located at each magnetic cusp. These spots were observed to streak along the center of the magnetic cusp. Also observed in Figure $8 \mathrm{~b}$ is an intense plasma excitation (discharge currents $\sim 10 \mathrm{~mA}$ ) emanating from one cathode spot to the edge of an adjacent magnetic cusp. The excitation is likely due to mirroring energetic electrons confined to oscillate between magnetic cusps. The fact that the dust particles are removed almost exclusively at the magnetic cusps suggests a means to control where the dust streams are formed.

Dust removal was also investigated without magnets in the dust holder. Without magnets, cathode spots appeared to be randomly dispersed across the surface of the electrode, with dust removal being equally likely at essentially all parts of the dust holder. This observation is consistent with observed texturing of the dust holding electrode surface. Figure 9a shows textured cathode spot tracks on the electrode surface after a test without magnets. The lighter regions represent regions of dust removal and thus cathode spot propagation. Figure 9b shows spots observed during testing. Multiple spots were observed to move around the dust-holding electrode's surface.

A four by four array of $1.27 \mathrm{~cm}$ diameter carbon witness badges were attached to the inside surface of the quartz window located above the dust holder cup. The carbon witness badges contained an adhesive backing that allowed for direct attachment to the plasma source's top window. The purpose of the witness badges was to serve as a deposition diagnostic to monitor ejected dust impacts at the top window. This window was located approximately $30 \mathrm{~cm}$ above the dust holder. Light microscope photographs of the witness badges are shown in Figure 10. Impact craters formed by energetic dust particles were observed on the soft carbon badges. These photographs were taken using $20 \mathrm{X}$ magnification. The observations indicated that the dust stream was sufficiently energetic to damage the surface of the carbon witness badges.

The findings of this initial investigation suggest that micron- to submicron sized particle streams can be generated via the approached described here. Provided the incident energies of the particles are sufficiently high, then this relatively simple and low cost approach may be applicable for the simulation of micrometeoroid impacts. In addition to the simulation of micrometeoroid impacts, this approach may also be adaptable for the deposition or implantation of nanoparticles into substrates. Deposition of nanoparticles onto substrates can significantly alter the physical properties of substrates. ${ }^{24}$ Using this approach, nanoparticle beams of variable energies could potentially be used for such deposition/implantation applications. Because of the nature of the plasma source (low pressure, moderate plasma density) deposition and implantation can occur at very low pressures, minimizing background gas incorporation or scattering effects. This approach is also material independent. The nanoparticles of choice to be deposited are simply loaded onto the dust holder electrode. These advantages are to be compared with existing nanoparticle approaches such as the synthesizing arcjet. ${ }^{25,26}$

The work presented here demonstrates that dust streams can be generated using the described approach. The implantation of particles into the carbon film suggests that the particles have net energies when reaching the target. Further characterization of the dust streams is necessary to determine the actual energies of the particles that make up the stream. Knowledge of the initial velocities of particles making up the dust stream is necessary to determine whether a bias at the target is needed or not. Measurements utilizing time of flight mass spectroscopy or 
laser-based particle image velocimetry ${ }^{27}$ can be used to fully characterize the actual energy spectra. Such a characterization is left to future work.

\section{References}

1. National Research Council, Orbital Debris: A Technical Assessment, Chapters 4-5, pp. 79-117, National Academy Press, Washington, DC, 1995.

2. Belk, C.A., Robinson, J.H., Alexander, M.B., Cooke, W.J., and Pavelitz, S.D., "Meteoroids and Orbital Debris: Effects on Spacecraft,” NASA Reference Publication 1408, August 1997.

3. Horanyi, Mihaly, Phys of Plasmas, vol. 7, no. 10, pp. 3847-3850, 2000.

4. “Micrometeoroid protection,” Practice NO. PD-EC-1107, May 1996.

5. Fechtig, H. Grun, E., and Kissel, J., in Cosmic Dust, ed. McDonnell, J.A.M., John Wiley and Sons, New York, pp. 623-637.

6. Schonberg, W.P., Characterizing Secondary Debris Impact Ejecta, NASA/CR—99-209561.

7. Cosmic Dust, pp. 607-622.

8. Vedder, J.F., Rev. Sci. Instrum., 34, 1175, 1963.

9. Urban III, F.K. et al., J. Vac Sci Technol. B, 20(3), May/June 2002.

10. Chen, F., Introduction Plasma Physics, Plenum Press, New York, pp. 290-296, 1984.

11. Hollenstein, C., Plasma Phys. Control. Fusion, 42, (2000) R93-R104.

12. Thomas, E. and Watson, M, Phys. Plasma, 6 (10): 4111-4117, Oct. 1999.

13. Chapman, B.N., Glow discharge processes: sputtering and etching, John Wiley and Sons, 1980.

14. Roth, J.R., Industrial Plasma Engineering: Vol. 1, IOP publishing, Philadelphia, 2000, p. 356.

15. Hantzsche, E., IEEE Transactions on Plasma Science, vol. 21, no. 5, Oct. 1993, pp. 419-425.

16. Schrade, H.O., IEEE Transactions on Plasma Science, vol. 17, no. 5, Oct. 1989, pp. 635-637.

17. Beilis, I., IEEE Transactions on Plasma Science, vol. 29, no. 5, Oct. 2001, pp. 657-670.

18. Schwirzke, F., IEEE Transactions on Plasma Science, vol. 21, no. 5, Oct. 1993, pp. 410-415.

19. Ivanov, R.Y., Puzanov, S.V., and Yashnov, Y.M., IEEE Transactions on Plasma Science, vol. 23, no. 6, Dec. 1995, pp. 899-901.

20. Ehlers, K.W. and Leung, K.N., Applied Phys. Lett, vol. 38, no. 4, 1981, pp. 287-289.

21. Swift, J.D. and Schwar, M.J.R., Electrical Probes for Plasma Diagnostics, London, Iliffe Books, Chapter 7, pp. 137-155.

22. Selwyn, G.S. et al., J. Vac. Sci. Technol. A7, 2758, 1988.

23. Urban, F.K., et al., J. Vac. Sci. Technol. B, vol. 20, Issue 3, May 2002.

24. Blun, J. et al., Journal of Nanoparticle Research, 1, pp. 31-42, 1999.

25. Rao, N.P., Girshick, S.L., McMurry, P.H., and Heberstein, J.V.R., U.S. Patent Number 5874134, Feb. 23, 1999.

26. Iordanoglov, D. et al., "Deposition of nanostructured films by hypersonic impaction of nanoparticles," $18^{\text {th }}$ Annual AAAR Conference, Tacoma, WA, Oct. 11-15, p. 203, 1999.

27. Thomas, E., IEEE TRANSACTIONS ON PLASMA SCIENCE 30 (1): 88-89 Part 1 FEB, 2002. 


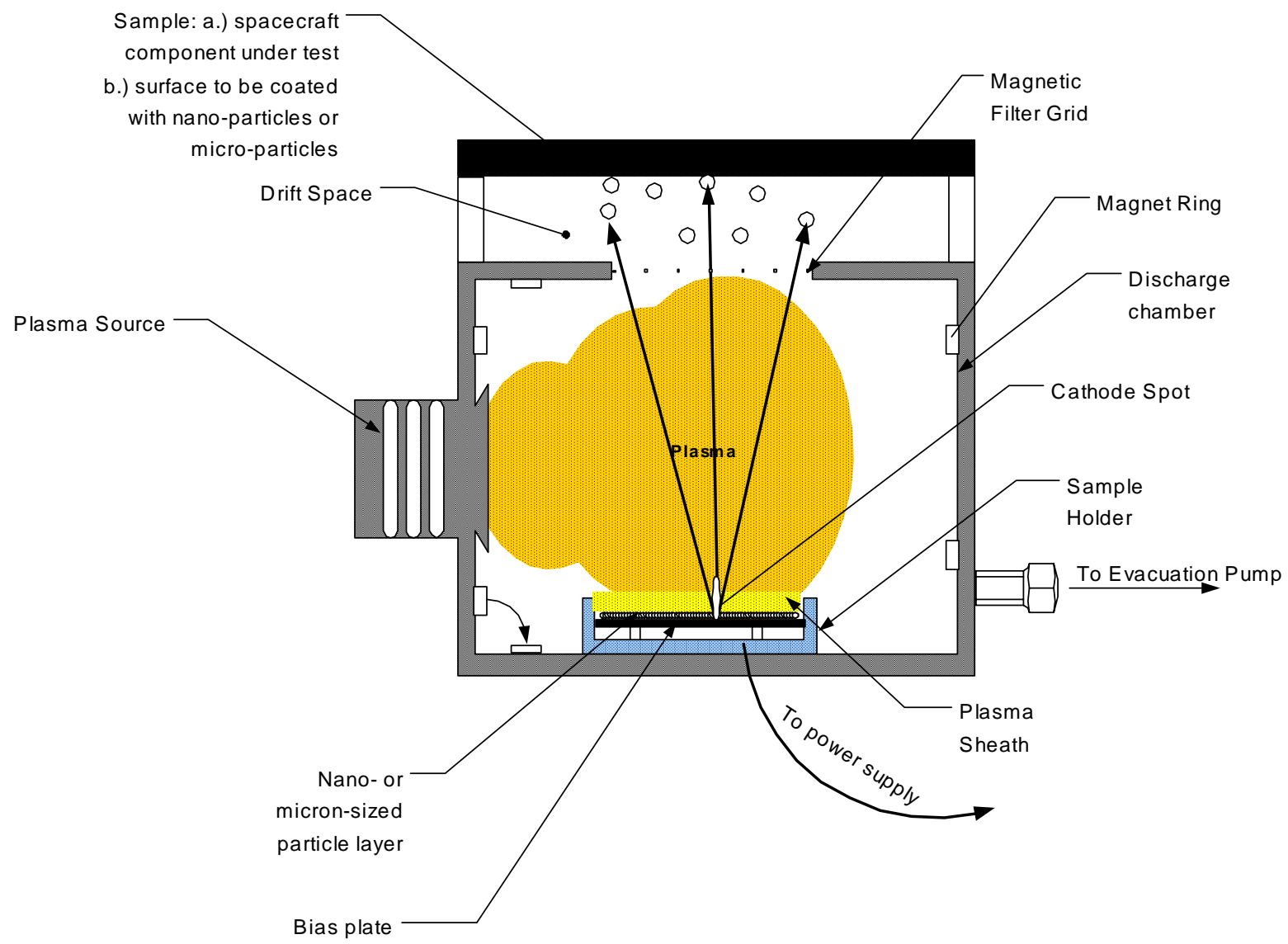

Figure 1. Conceptual design of dust particle accelerator apparatus. Exposure to the discharge plasma produces negatively charged particles. 


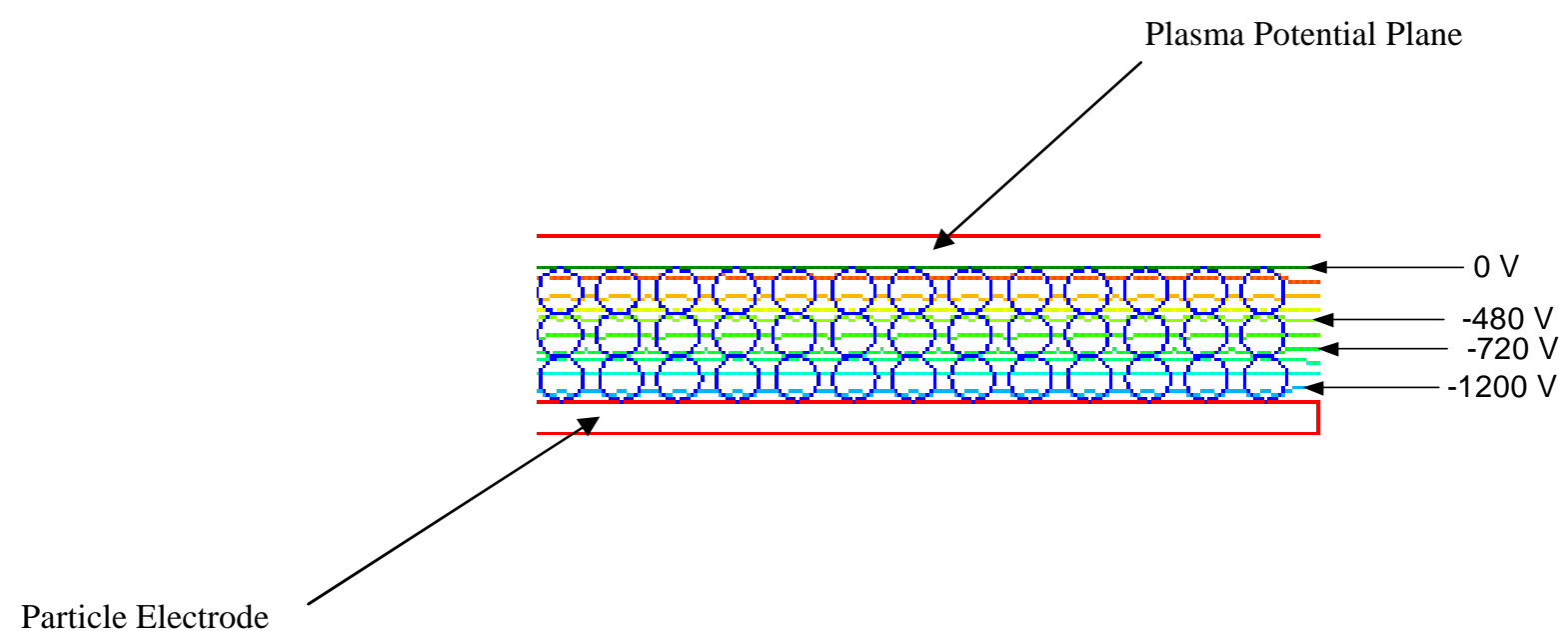

Figure 2a. Calculated potential profiles for 45 micron alumina particles near the electrode surface. Here the electrode surface is biased at $-1200 \mathrm{~V}$ with respect to local plasma potential.

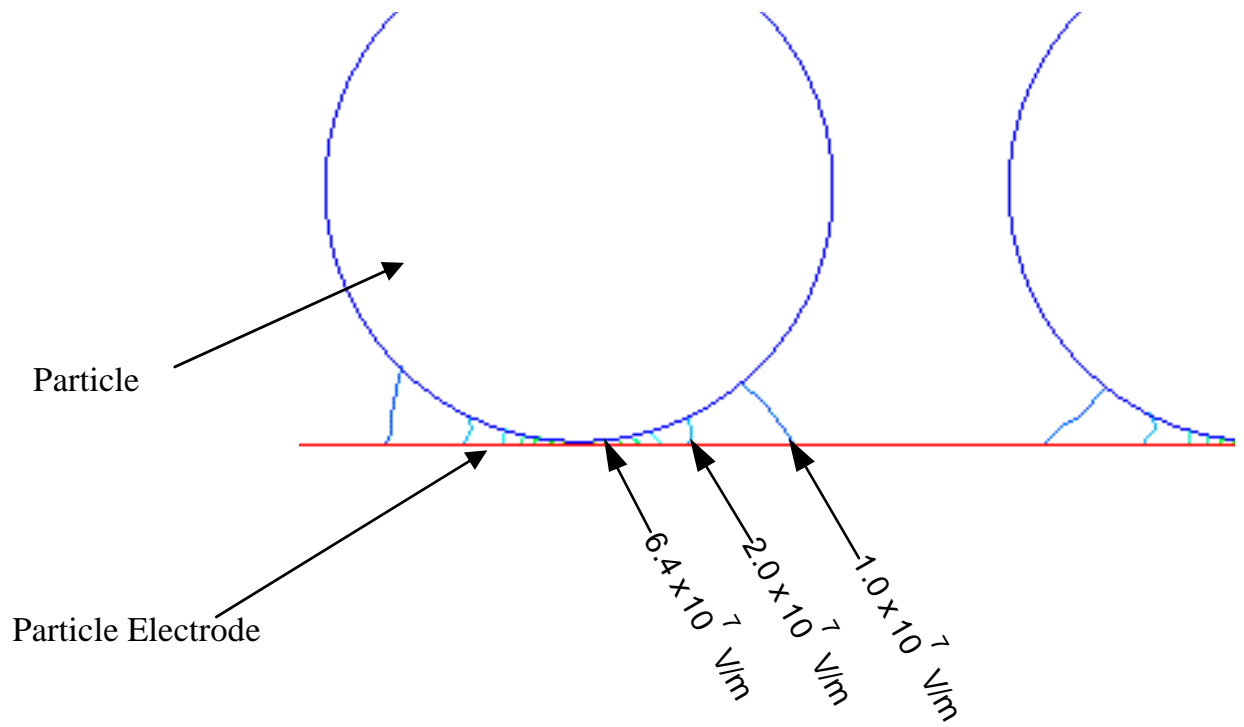

Figure 2b. Calculated electric field profiles between 45 micron alumina particle and electrode surface. Note electric field intensity near dust particle base. Such large electric fields can initiate field emission and subsequent formation of cathode spots. 


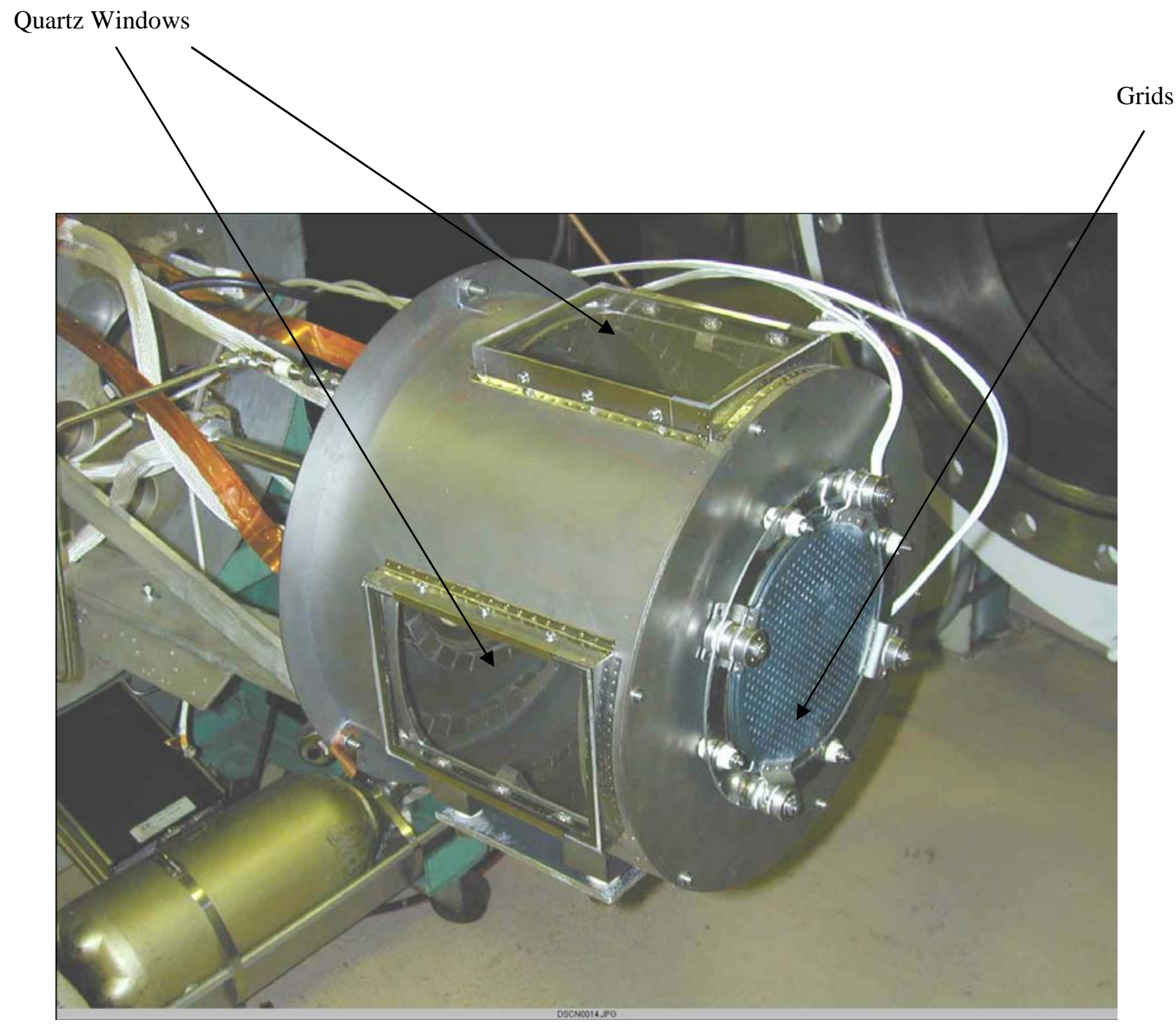

Figure 3a. Multipole source with quartz windows to accommodate observation of dust stream formation. 

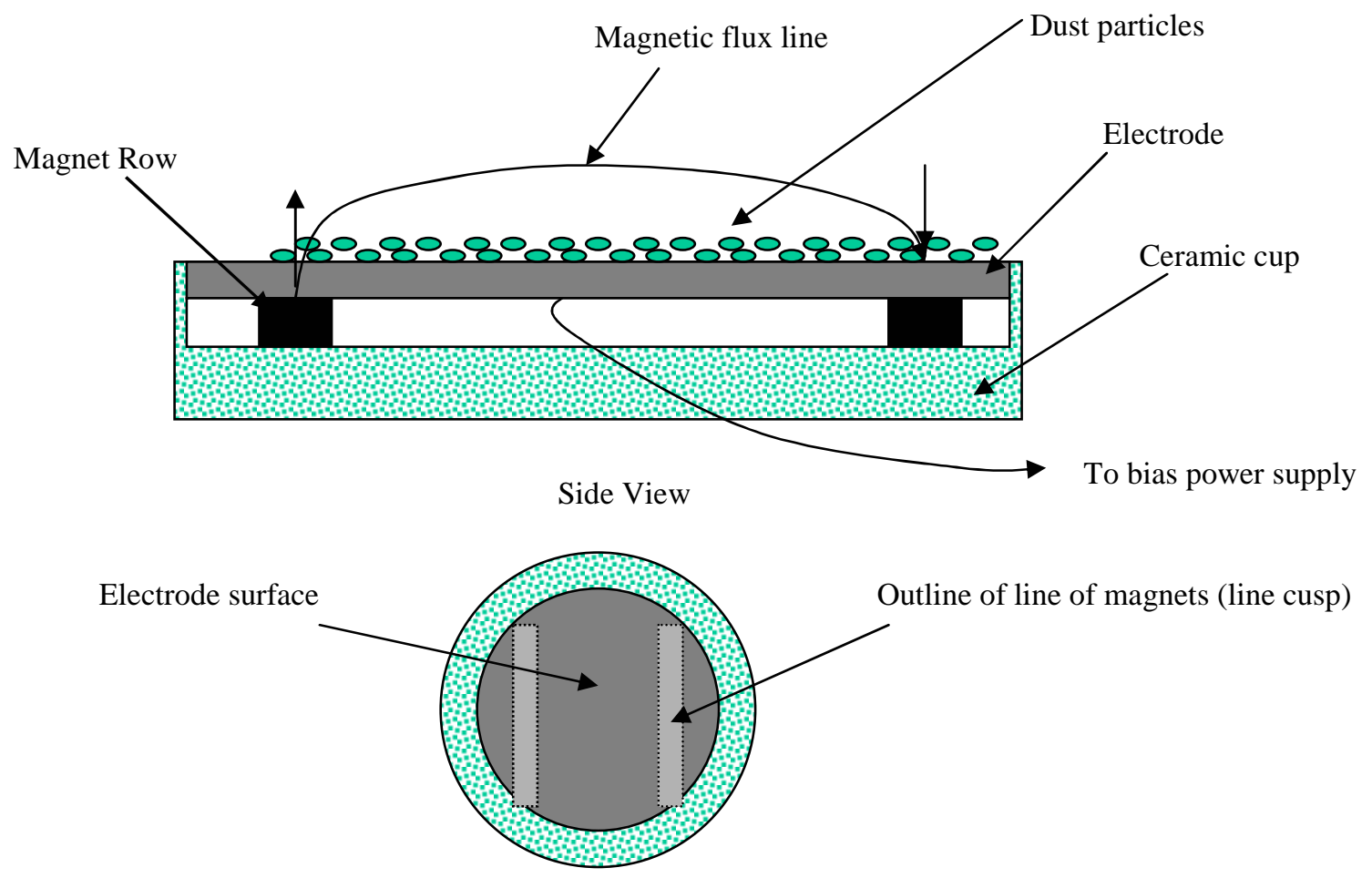

Top view

Figure 3b. Biasable dust holding electrode. Note position of magnetic line cusps. 


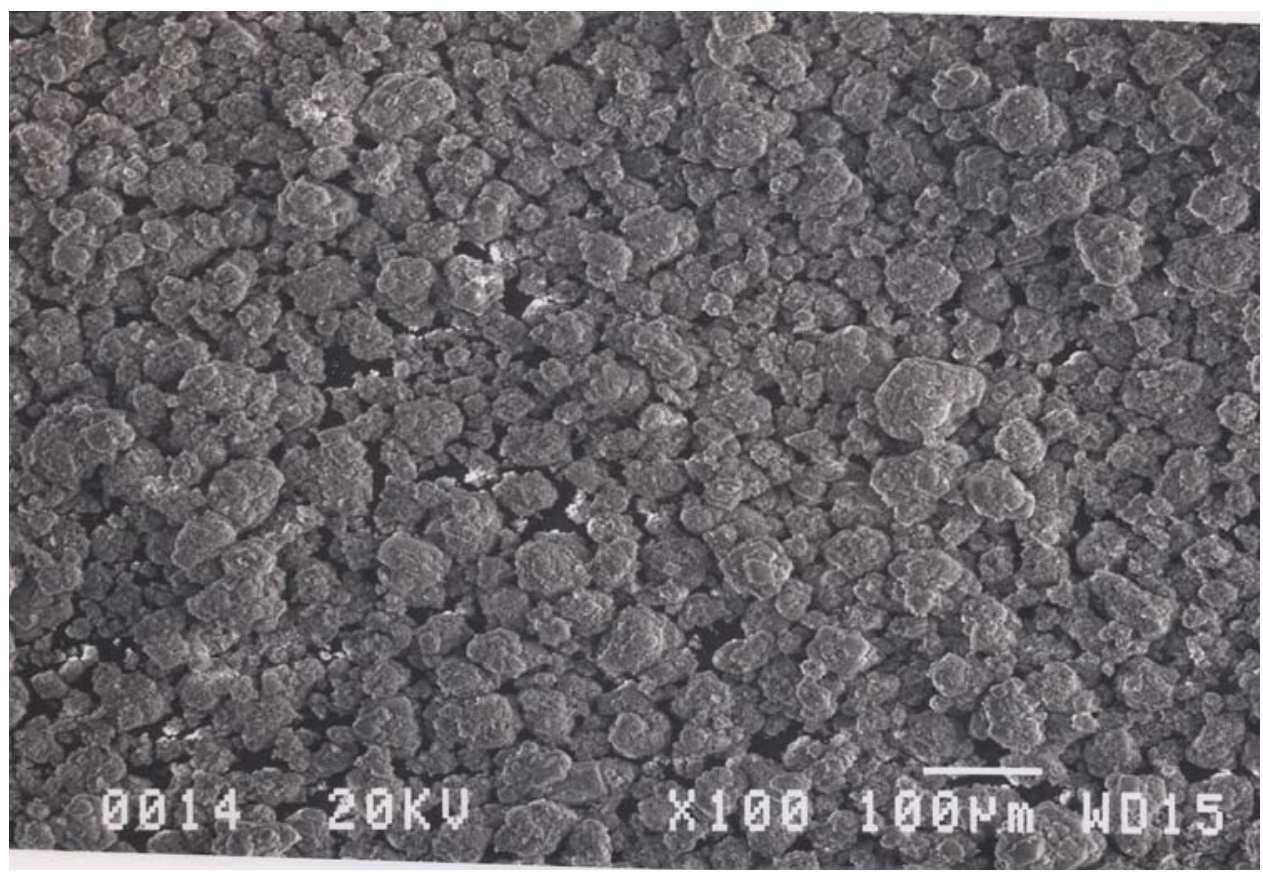

Figure 4. SEM photograph of alumina powder. Irregularly shaped particles have an average diameter of 45 micrometers.

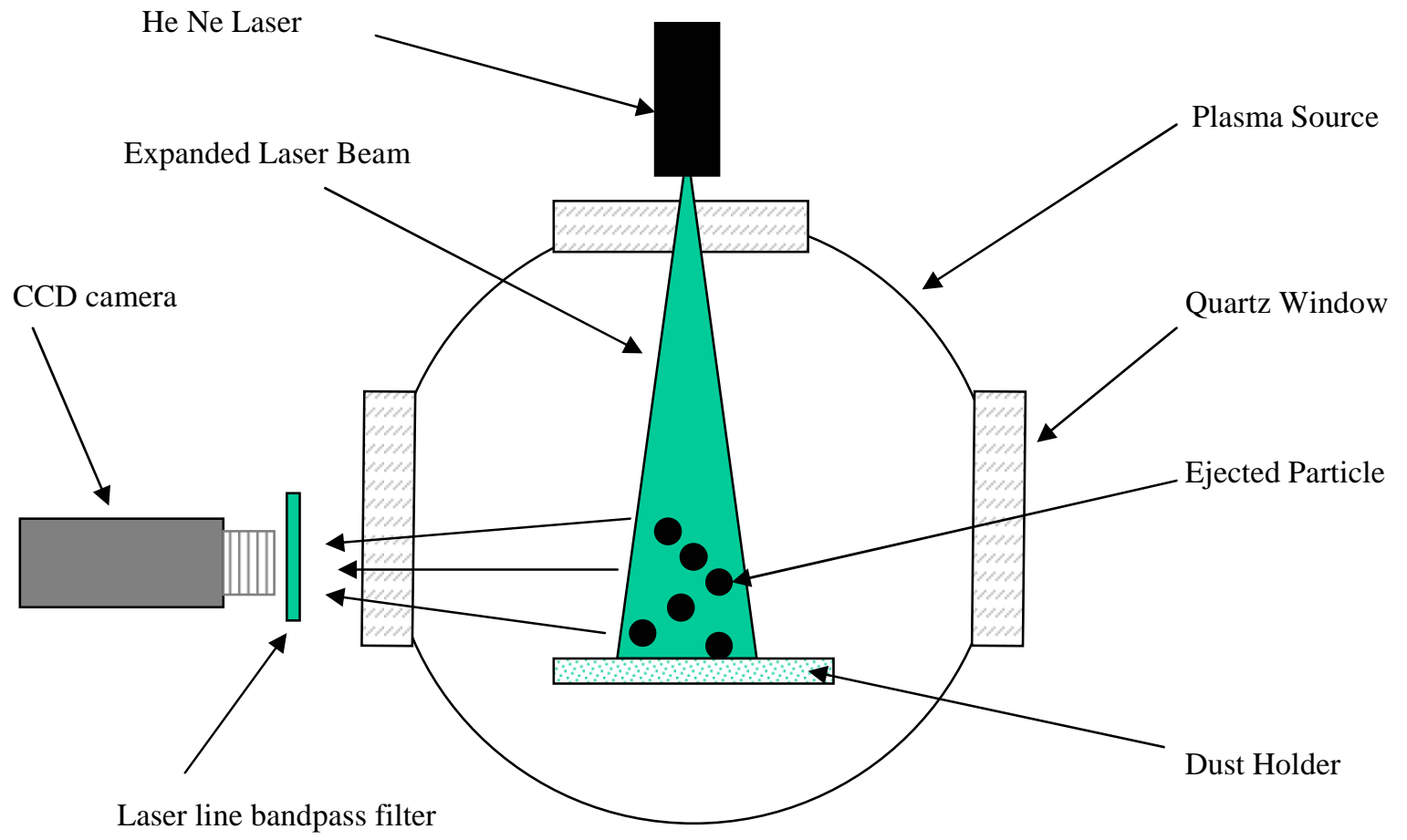

Figure 5. Laser light scattering apparatus used to detect the formation of alumina dust streams. Light from a Helium Neon laser is scattered onto a ccd camera fitted with a laser line filter. 


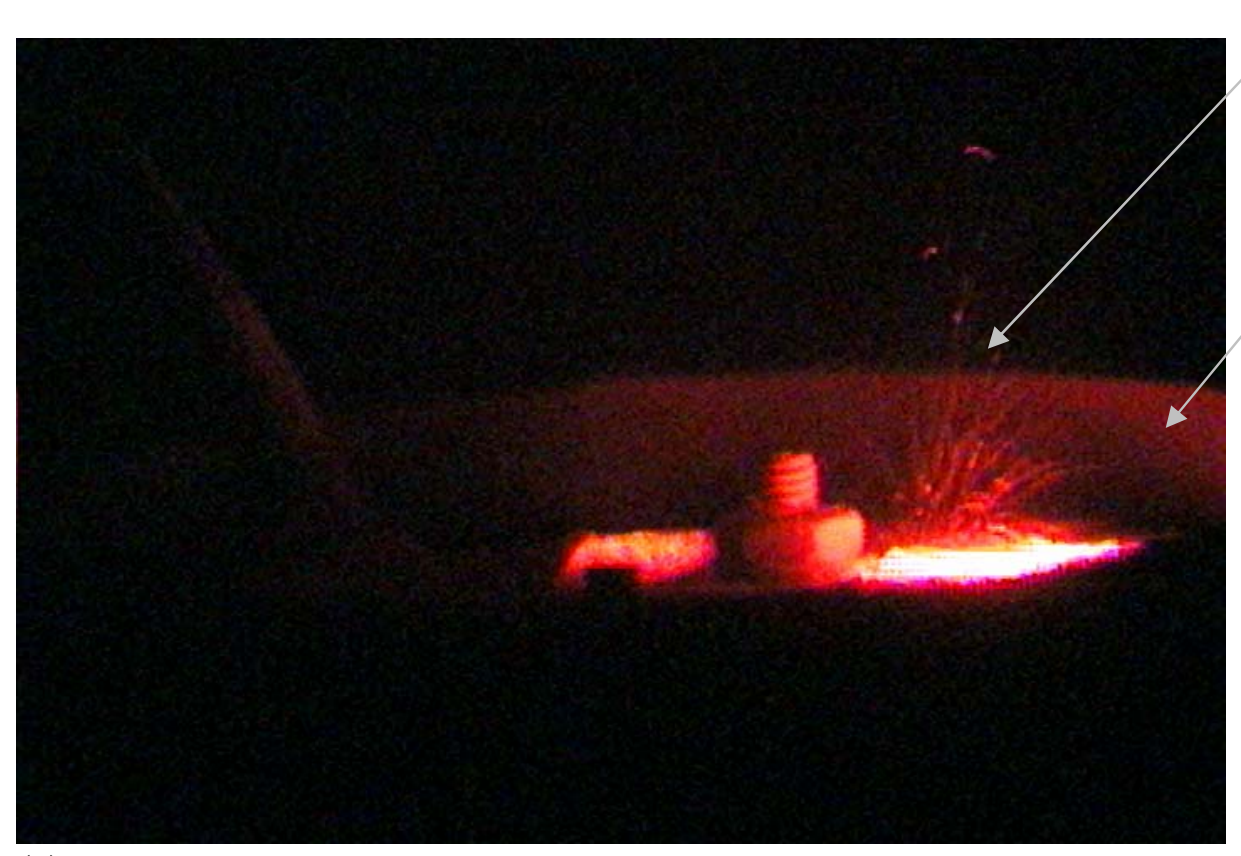

Dust Holder

(a)

Dust Streams

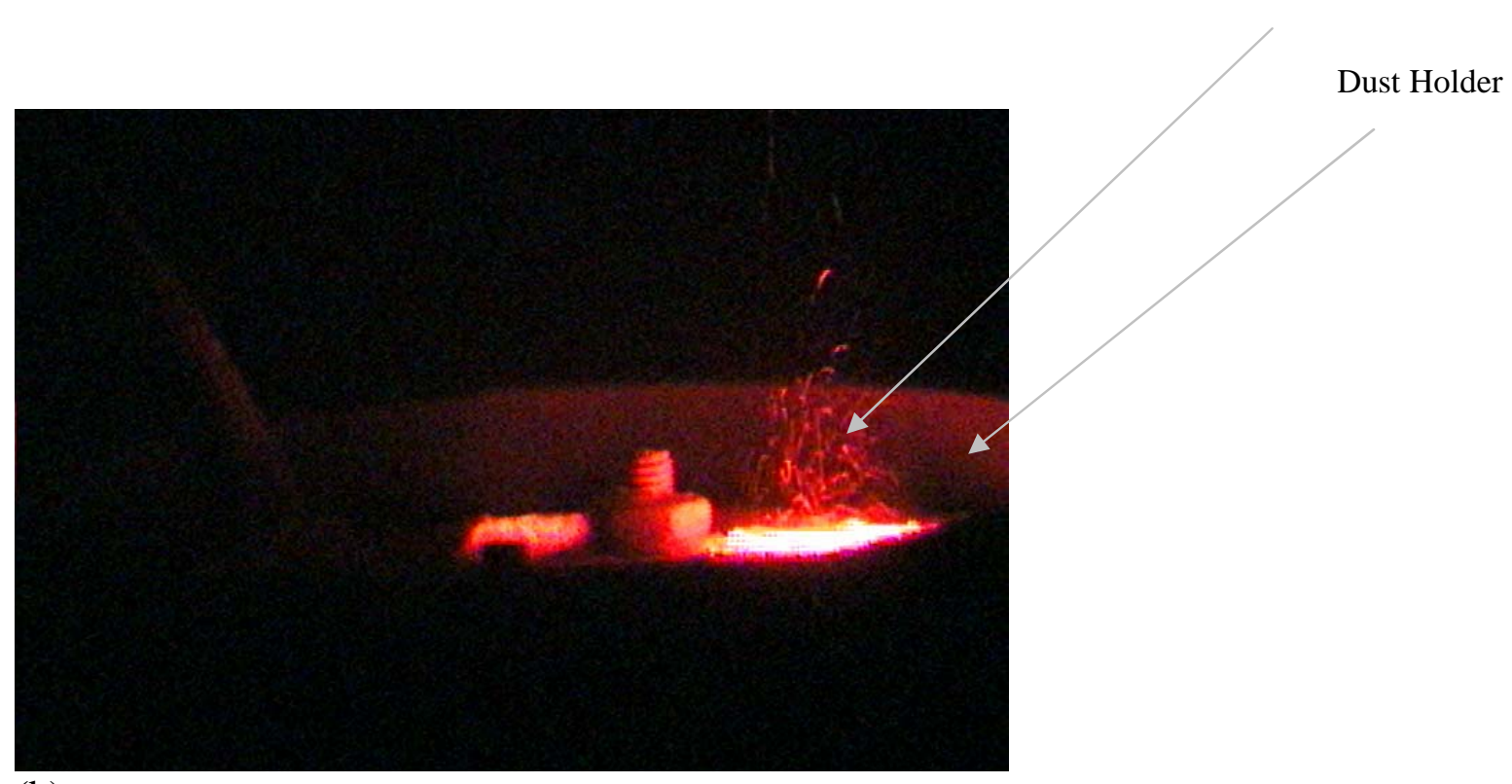

(b)

Figure $6 \mathrm{a}$ and $\mathrm{b}$. Alumina dust streams made visible using laser scattering. Note the streaks. Some trajectories are parabolic indicating the ejection of conglomerates 45 micron particles clumped together. 


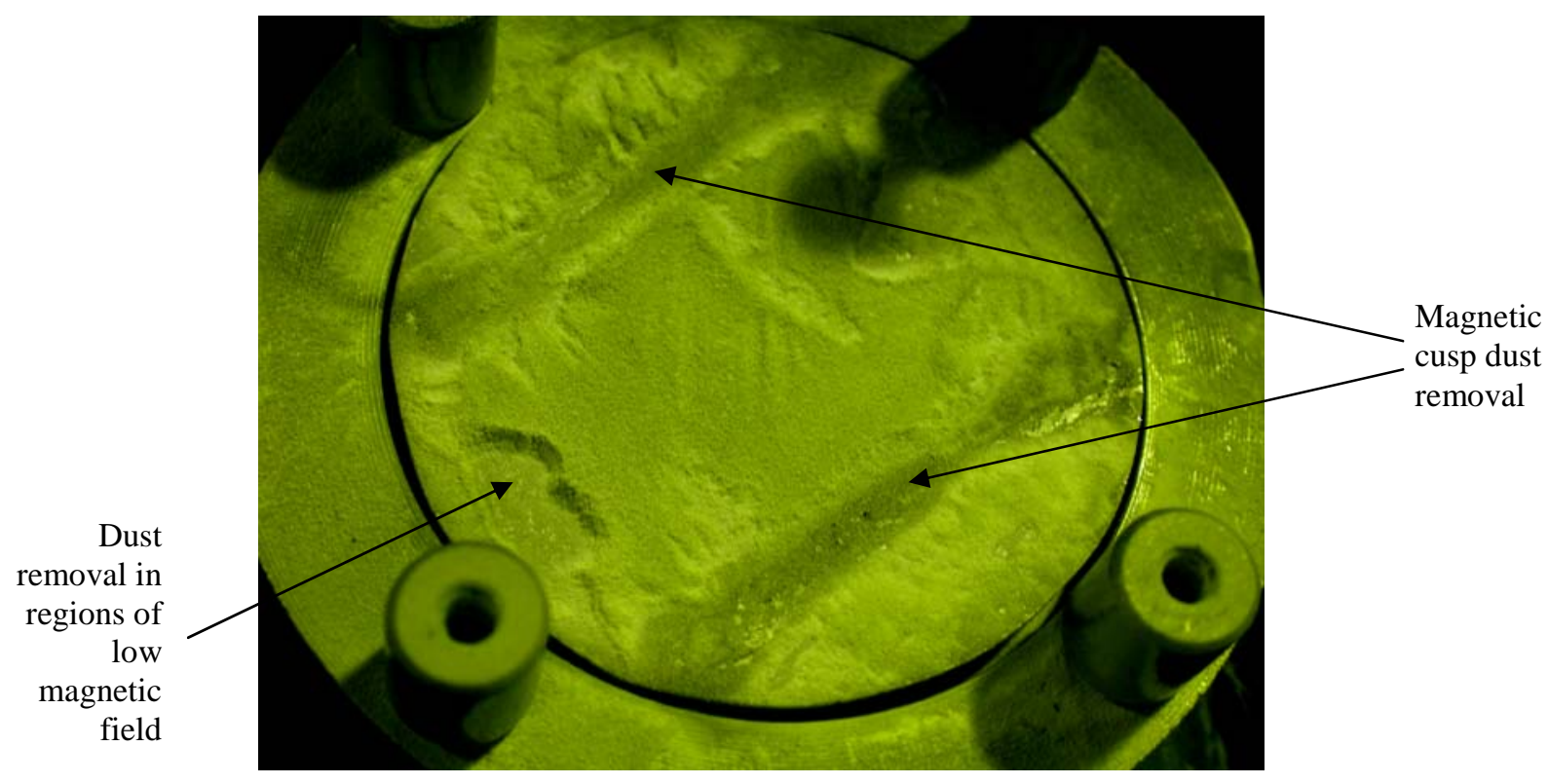

Figure 7a. Tracks left upon the surface of the dust layer as observed after test.

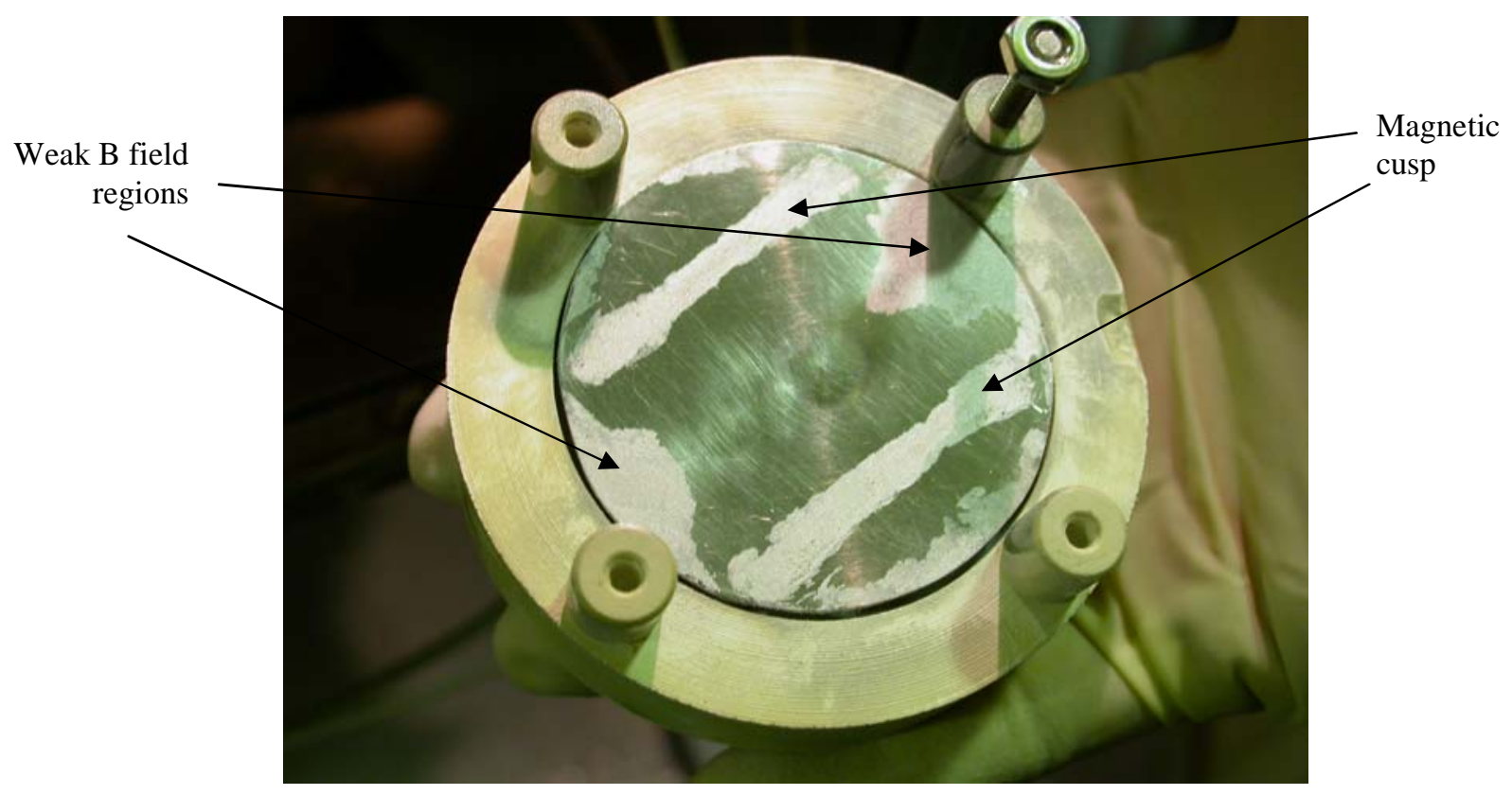

Figure 7b. Cathode spot tracks observed on the surface of the metal.

Observed the textured surface of the stainless steel electrode. 


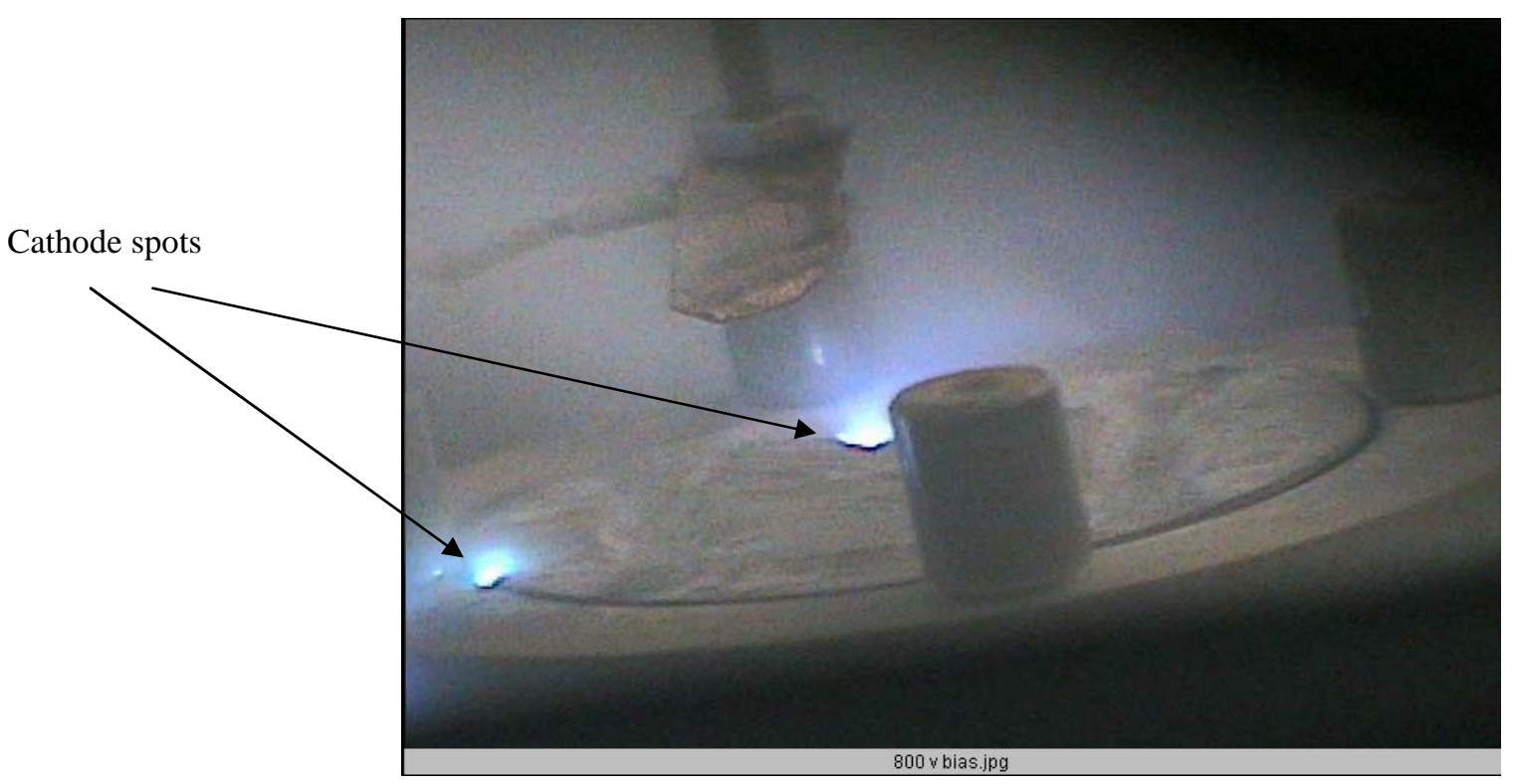

Figure 8a. Cathode spot formation at a magnetic cusp and at electrode edge.

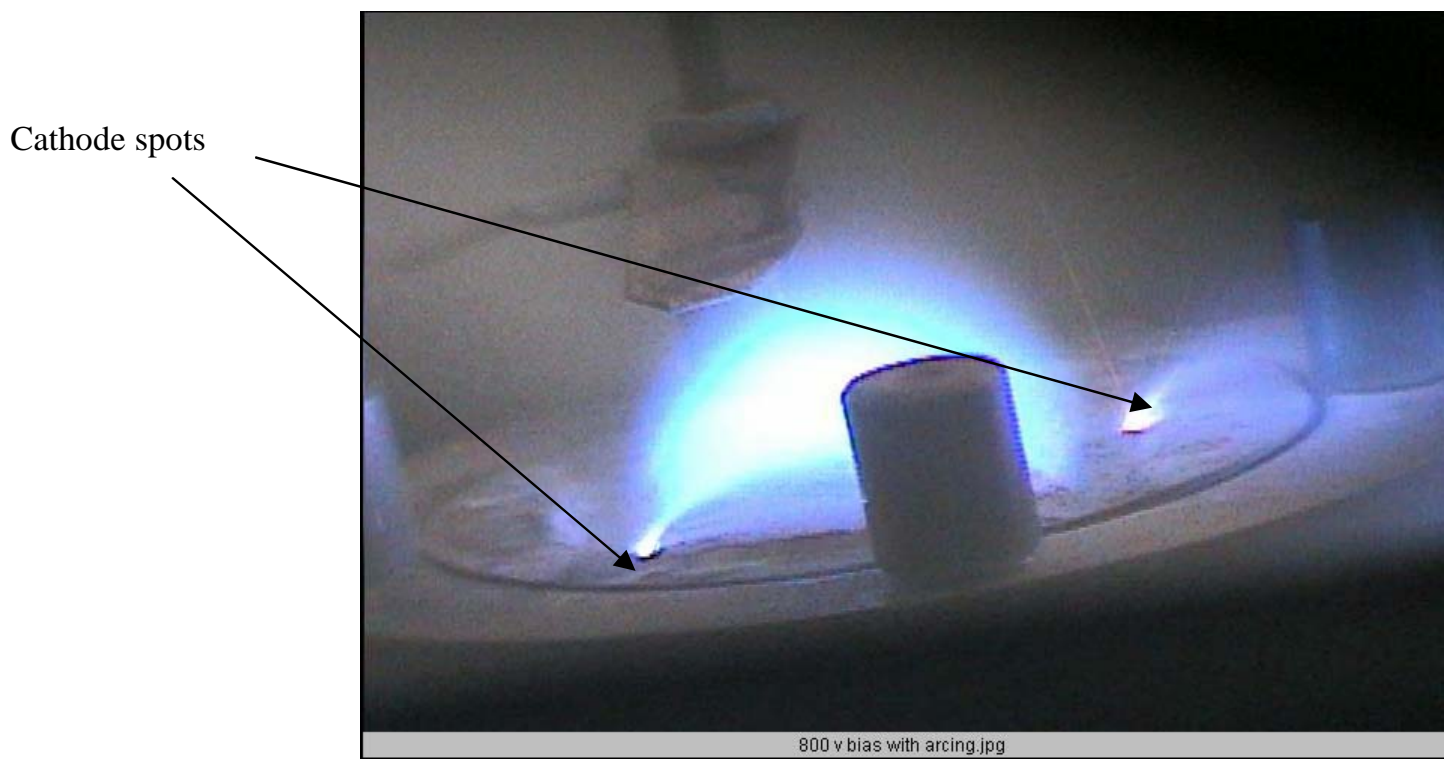

Figure 8b. Observation of two cathode spots localized to the center of the magnetic cusps. Also note intense plasma excitation along arcs between the magnetic cusps. 


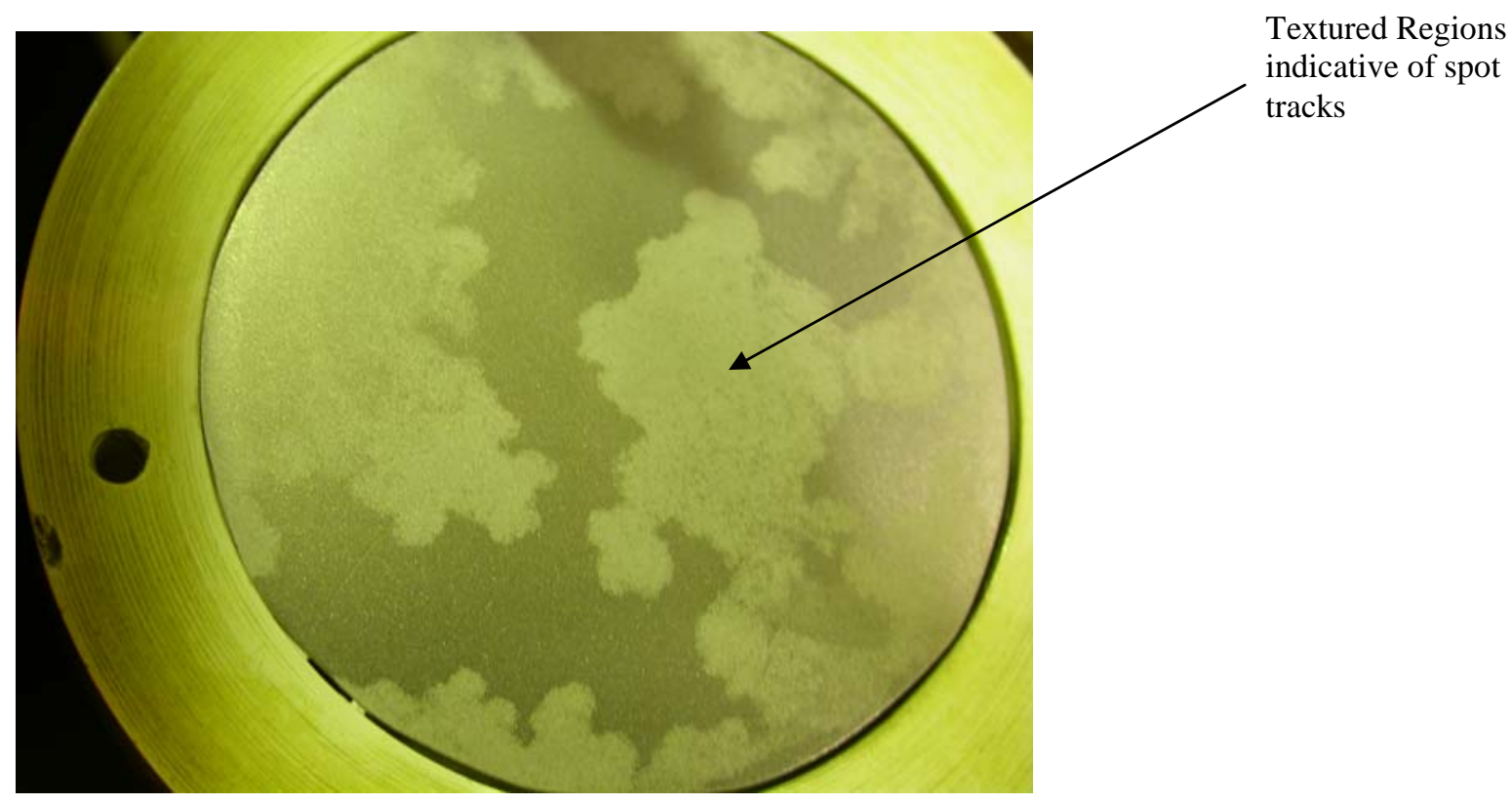

Figure 9a. Textured electrode surface after operation without magnets in dust holder.

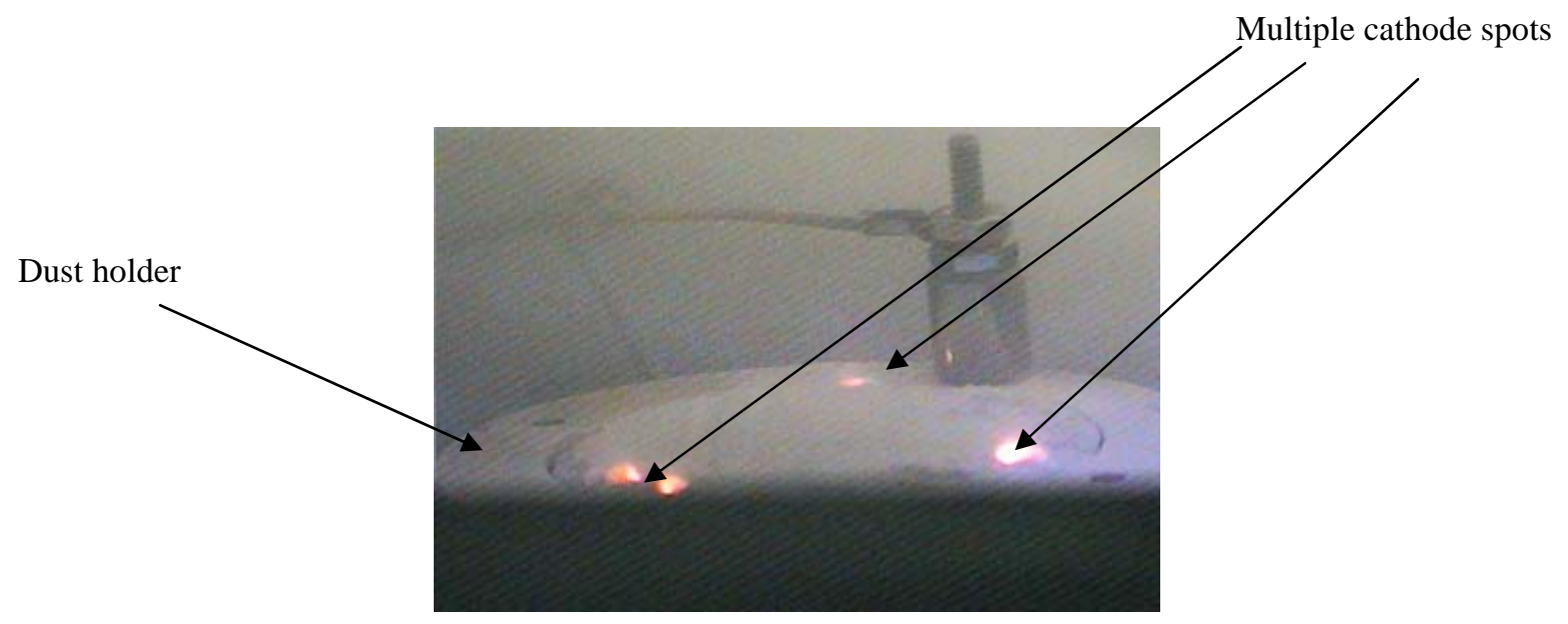

Figure 9b. Observed cathode spots during operation without magnets in dust holder. 

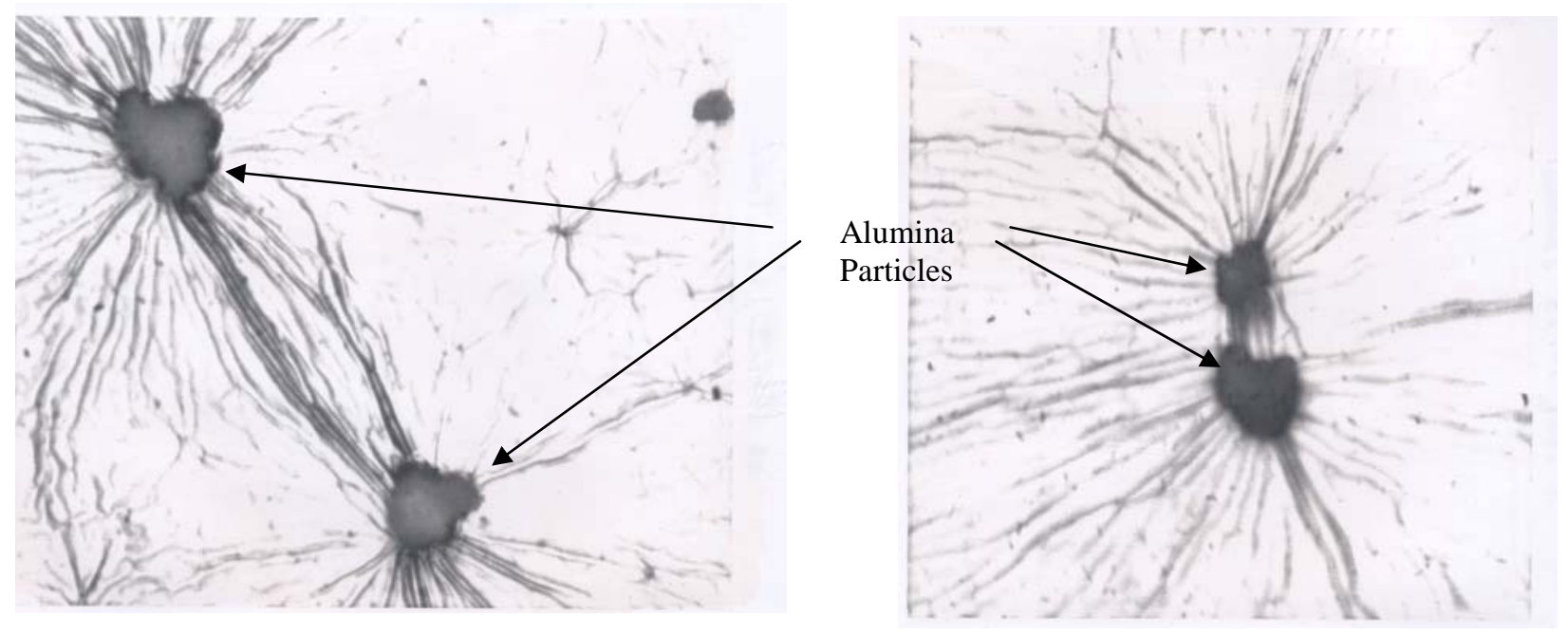

Figure 10. Alumina particle impact craters in carbon mesh targets as imaged using a light microscope. 



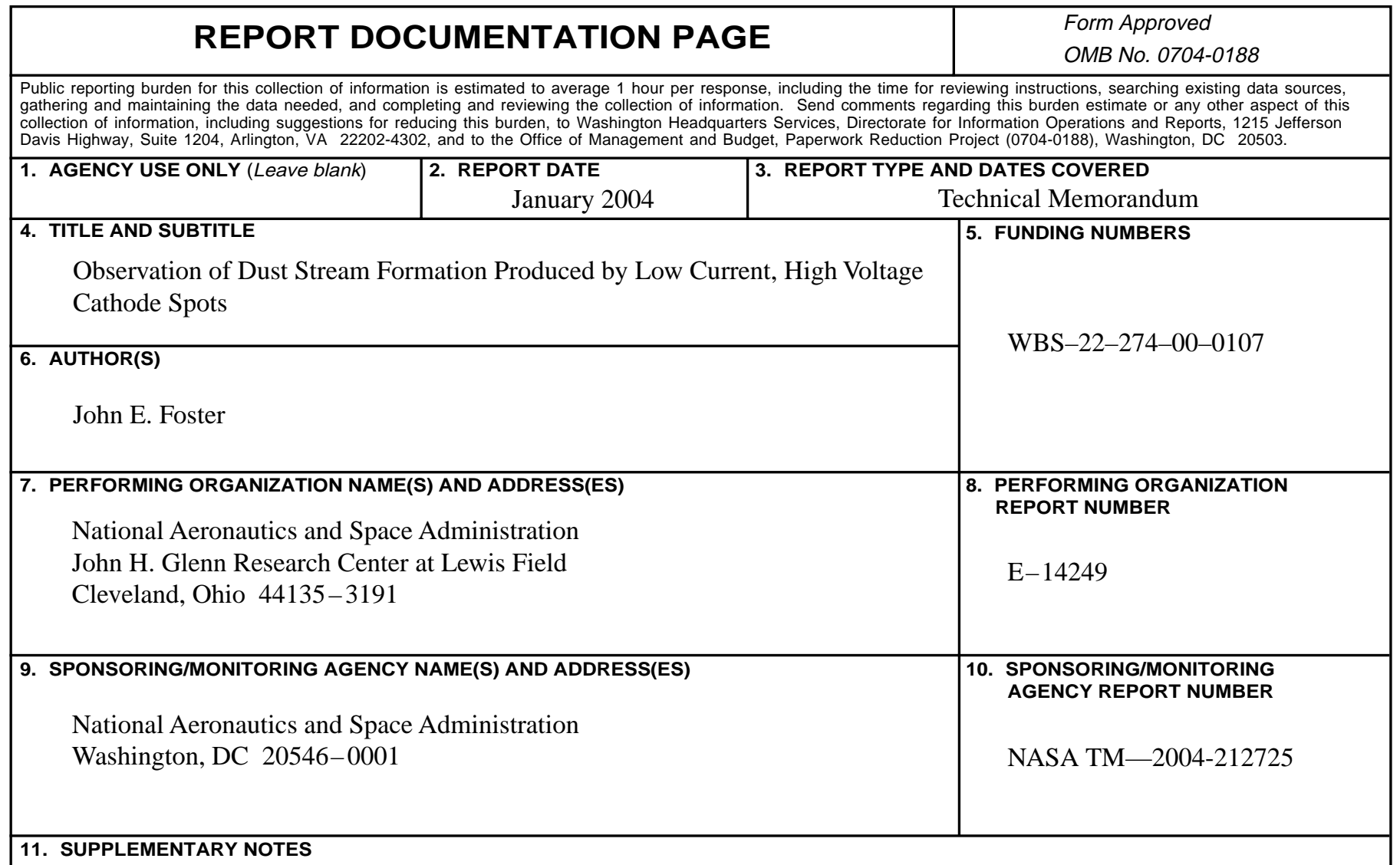

Responsible person, John E. Foster, organization code 5430, 216-433-6131.

12a. DISTRIBUTION/AVAILABILITY STATEMENT

12b. DISTRIBUTION CODE

Unclassified - Unlimited

Subject Categories: 88 and 75

Distribution: Nonstandard

Available electronically at http://gltrs.grc.nasa.gov

This publication is available from the NASA Center for AeroSpace Information, 301-621-0390.

13. ABSTRACT (Maximum 200 words)

Macro-particle acceleration driven by low current, high voltage cathode spots has been investigated. The phenomenon was observed to occur when nanometer and micrometer-sized particles in the presence of a discharge plasma were exposed to a high voltage pulse. The negative voltage pulse initiates the formation of multiple, high voltage, low current cathode spots which provides the mechanism of actual acceleration of the charged dust particles. Dust streams generated by this process were detected using laser scattering techniques. The particle impact craters observed at the surface of downstream witness badges were documented using SEM and light microscopy.

14. SUBJECT TERMS

\begin{tabular}{|l|l|} 
& $\begin{array}{c}15 . \text { NUMBER OF PAGES } \\
24\end{array}$ \\
\cline { 2 - 2 } & 16. PRICE CODE \\
$\begin{array}{l}\text { 19. SECURITY CLASSIFICATION } \\
\text { OF ABSTRACT } \\
\text { Unclassified }\end{array}$ & 20. LIMITATION OF ABSTRACT \\
\hline
\end{tabular}

NSN 7540-01-280-5500

Standard Form 298 (Rev. 2-89)

Prescribed by ANSI Std. Z39-18 298-102 